\title{
Different respiratory phenotypes are associated with isocyanate exposure
} in spray painters

\author{
A. Pronk*\#, L. Preller\#, G. Doekes*, I.M. Wouters*, J. Rooijackers", \\ J-W. Lammers ${ }^{+}$and D. Heederik ${ }^{\star}, \S$
}

ABSTRACT: Associations have been observed between exposure to isocyanates, consisting mainly of oligomers, and respiratory symptoms and isocyanate specific sensitisation in spray painters. The aim of the present study was to assess associations between isocyanate exposure and more objective respiratory effect measures such as bronchial hyperresponsiveness (BHR), baseline spirometry and exhaled nitric oxide (eNO) in a subset of spray painters.

Methacholine challenge and eNO measurements were performed in 229 workers. Questionnaires and blood samples were obtained. Specific immunoglobulin (Ig)E and IgG to hexamethylene di-isocyanate were assessed in serum using various assays. Personal exposure was estimated by combining personal task-based inhalatory exposure measurements and timeactivity information.

Workers with higher isocyanate exposure were more often hyperresponsive (prevalence ratio comparing the 75 th versus 25th percentile of exposure 1.8). In addition, significant exposure-

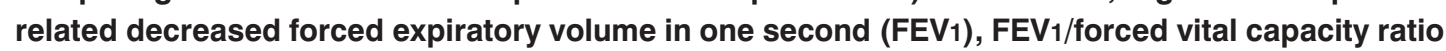
and flow-volume parameters independent of BHR were found. BHR was more prevalent among sensitised workers. This was statistically significant for only IgG-ImmunoCAP (Phadia, Uppsala, Sweden) positive workers. eNO was not associated with exposure although slightly elevated eNO levels in specific IgG positive subjects were found.

The current study provides evidence that exposure to isocyanate oligomers is related to asthma with bronchial hyperresponsiveness as a hallmark, but also shows independent chronic obstructive respiratory effects resulting from isocyanate exposure.

KEYWORDS: Bronchial hyperresponsiveness, hexamethylene di-isocyanate, oligomer, sensitisation, spirometry, spray painter

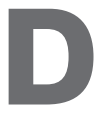
i-isocyanates are among the most common causes of occupational asthma [1-3]. Although asthma is considered the major health effect, hypersensitivity pneumonitis and accelerated lung function decline have also been related to di-isocyanate exposure [4]. Di-isocyanate monomers are characterised by two highly reactive isocyanate (NCO) groups and are used as polymerising agents in polyurethane products [5]. Most of the evidence regarding health effects from di-isocyanates involves these monomers. Lately, isocyanate oligomers or poly-isocyanates, with lower vapour pressure, have been introduced to reduce inhalatory exposure. These are increasingly being used and currently many workers are exposed to complex mixtures of isocyanate oligomers. Exposure assessment for these agents is challenging [6] and few epidemiological studies incorporated an exposure assessment component. As a result, exposure-response information for isocyanate oligomers is extremely limited.

The present authors recently demonstrated an association between exposure and (work-related) respiratory symptoms and isocyanate-specific sensitisation in a population of 581 spray painters exposed to mainly hexamethylene di-isocyanate (HDI) oligomers [7]. To further investigate the nature of respiratory health effects caused by isocyanates, a more detailed medical evaluation was performed in a subset of the current population. The present authors hypothesised that exposure to isocyanates is associated with bronchial hyperresponsiveness (BHR) as a hallmark of asthma, baseline lung function and exhaled nitric oxide (eNO) as a marker of respiratory inflammation.

\section{AFFILIATIONS}

*Environmental Epidemiology, Institute for Risk Assessment Sciences, Utrecht University, "Netherlands Expertise Centre for Occupational Respiratory Disorders, Heart Lung Centre Utrecht,

${ }^{+}$Dept of Pulmonary Diseases, University Medical Centre Uterecht, ${ }^{\S}$ Julius Centre for Health Sciences and Primary Care, University Medical Centre Utrecht, Utrecht, and

\#Business Unit Quality and Safety TNO Quality of Life, Zeist, The Netherlands.

\section{CORRESPONDENCE}

D. Heederik

Institute for Risk Assessment

Sciences, Division Environmental

Epidemiology

Utrecht University

PO Box 80176

3508 TD Utrecht

The Netherlands

Fax: 31302539499

E-mail: D.Heederik@iras.uu.nl

Received:

June 162008

Accepted after revision:

November 182008

SUPPORT STATEMENT

This study was funded by the

Ministry of Social Affairs and

Employment (The Netherlands) and by CEFIC (Brussels, Belgium) under the Long Range Research Initiative.

STATEMENT OF INTEREST

None declared.

European Respiratory Journal

Print ISSN 0903-1936

Online ISSN 1399-3003 


\section{METHODS}

\section{Population and study design}

The current cross-sectional study was carried out in a subset of a population of workers in the Dutch spray painting industry [7]. At the time of selection, results for specific antibodies against diisocyanates measured by ImmunoCAP assay (Phadia, Uppsala, Sweden) were available from the baseline population. All workers from companies with at least one worker with detectable specific di-isocyanate immunoglobulin (Ig)E or IgG antibodies were invited to participate in the present study. Companies were visited between January and June 2006. All tests were carried out on a working day at the company premises.

The institutional review board for human studies of the University Medical Centre Utrecht (Utrecht, the Netherlands), approved of the protocols and written consent was obtained from all participants.

\section{Questionnaire and exposure estimates}

Questionnaire items were as previously described [7]. For statistical analyses respiratory symptoms suggestive of chronic obstructive pulmonary disease (COPD) and asthma were clustered into: COPD-like symptoms (chronic cough, chronic phlegm or shortness of breath); and asthma-like symptoms (wheezing or chest tightness). Workers were classified into the following categories based on task information: office workers; spray painters; and others [7].

In total, more than 500 personal task-based inhalatory measurements were conducted in a random sample of the participating workers to assess exposure to 23 isocyanate compounds, as described previously [8]. Personal exposure estimates were obtained by combining measurement results and time-activity information [7]. Exposure was expressed as the total NCO exposure after summing individual monomer and oligomer levels.

\section{Serology}

Specific IgE and IgG to HDI were assessed in serum by the ImmunoCAP assay and enzyme immunoassays (EIAs) [7]. In EIAs, human serum albumin (HSA)-conjugates were used prepared with HDI in the vapour $\left(\mathrm{HDI}_{\mathrm{V}}-\mathrm{HSA}\right)$ and liquid ( $\left.\mathrm{HDI}_{\mathrm{L}}-\mathrm{HSA}\right)$ phase and prepared with commercial products containing oligomeric HDI (N3300-HSA and N100-HSA). Specific IgE to common aeroallergens was assessed using the Phadiatop (Phadia) as a measure of atopy. Cut-off values were used to dichotomise serological outcomes [7].

\section{Spirometry and methacholine challenge}

Baseline lung function parameters were obtained [7]. Only one technically acceptable manoeuvre could be obtained from 31 workers, while for all other workers at least two maximal expiratory flow-volume manoeuvres were obtained. BHR was assessed by a dosimeter method for methacholine challenge [7]. Airway hyperresponsiveness was defined as a provocative cumulative dose of methacholine of $\leqslant 2.5 \mathrm{mg}(\sim 10 \mu \mathrm{M})$ required to cause a $20 \%$ fall in forced expiratory volume in one second (FEV1).

\section{eNO}

A NIOX MINO ${ }_{\circledR}$ (Aerocrine AB, Solna, Sweden) handheld device was used to measure eNO according to the American
Thoracic Society/European Respiratory Society recommendations and manufacturer guidelines [9]. Nitric oxide (NO) free air was inhaled to total lung capacity through the device and then exhaled through the device for $10 \mathrm{~s}$. During exhalation the flow rate was kept constant at $50 \pm 5 \mathrm{~mL} \cdot \mathrm{s}^{-1}$ by a built-in flow control unit. The last 3-s portion of exhaled air was analysed by an electrochemical sensor in the device. One instrument and sensor was used, which were calibrated and validated at production using a known reference gas source of $\mathrm{NO}$ and several validated sensors, respectively. The performance of the electrochemical handheld NIOX $\mathrm{MINO}_{\circledast}$ has been compared with standard stationary chemiluminescence units, showing a strong correlation and a high degree of agreement [10-12].

\section{Statistical analysis}

For BHR, symptoms and serology the prevalence ratio (PR) with $95 \%$ confidence intervals (CI) was calculated as a measure of association [13] using log-binomial regression. Log-transformed exposure data were used and PRs were expressed per interquartile range (IQR) increase in NCO exposure: 0.3$2799 \mu \mathrm{g} \cdot \mathrm{m}^{-3} \cdot \mathrm{h} \cdot \mathrm{month}^{-1}$ (factor 9330). The shape of the associations between exposure and BHR was further explored by nonparametric regression modelling (smoothing) using generalised additive models. Smoothing parameter degrees of freedom were selected by generalised cross-validation [14] but were limited to a maximum of three. Associations for continuous health outcomes (lung function parameters and $\log$ transformed eNO) were assessed by linear regression. All associations were adjusted for current smoking, age, sex and atopy. For eNO, stratification was by two major determinants: atopy and smoking. Associations for lung function parameters were additionally adjusted for height and race. When, due to limited power, adjustments could not be made for all of these potential confounders together, the adjustments were made sequentially in separate models. This is mentioned in more detail in the study.

\section{RESULTS}

\section{Population characteristics}

In total, 229 workers from 38 companies participated in the present study. Of all the invited companies, $90 \%$ participated and the worker-participation rate within these companies was $66 \%$. Of the workers who did not participate, $27 \%$ refused, $22 \%$ were not present at the time of the study and $51 \%$ had left the company (50\% left for another company in the same industry, $25 \%$ left the industry and for $25 \%$ the new employer was not known).

General characteristics of the current study population and the prevalence of symptoms and serology are shown in table 1. Exposure mainly consisted of HDI oligomers, and HDI monomers contributed to a small fraction of total NCO. Spray painters had the highest exposure but the exposure distribution clearly overlapped with other workers. Spray painters tended to be somewhat younger and were more often smokers.

\section{Symptoms, serology and associations with exposure}

Asthma-like symptoms, COPD-like symptoms and workrelated chest tightness were more prevalent among workers with higher exposure but associations were not statistically significant (adjusted PR per IQR increase in exposure (95\% CI): 


\begin{tabular}{|c|c|c|c|}
\hline \multirow[t]{2}{*}{ TABLE 1} & \multirow[b]{2}{*}{ Office workers } & \multirow[b]{2}{*}{ Spray painters } & \multirow[b]{2}{*}{ Others } \\
\hline & & & \\
\hline \multicolumn{4}{|l|}{ Characteristics } \\
\hline Subjects $n$ & 20 & 91 & 118 \\
\hline Male \% & 80 & 98 & 99 \\
\hline \multicolumn{4}{|c|}{ Isocyanate exposure $\mu \mathrm{g} \cdot \mathrm{m}^{-3} \cdot \mathrm{h} \cdot \mathrm{month}^{-1}$} \\
\hline Total isocyanate & 0 & $4530(15.4-66464)$ & $5.6(0-3785)$ \\
\hline $\mathrm{HDI}$ & 0 & $36.2(1.3-472)$ & $0.7(0-354)$ \\
\hline \multicolumn{4}{|l|}{ Symptoms \% } \\
\hline COPD-like symptoms ${ }^{+}$ & 25.0 & 26.4 & 27.4 \\
\hline \multicolumn{4}{|l|}{ Serology \% } \\
\hline Atopy (Phadiatop) & 55.0 & $39.3^{f, \# \#}$ & $39.5^{f, \# \#}$ \\
\hline \multicolumn{4}{|l|}{ Specific anti-HDI IgE \% } \\
\hline HDI-ImmunoCAP & 0 & 2.3 & 1.8 \\
\hline $\mathrm{HDI}_{\mathrm{L}-\mathrm{HSA}}$ & 0 & 2.3 & 4.4 \\
\hline $\mathrm{HDI}_{\mathrm{V}}-\mathrm{HSA}$ & 0 & 0 & 1.8 \\
\hline N3300-HSA & 0 & 1.1 & 1.8 \\
\hline N100-HSA & 0 & 3.4 & 3.5 \\
\hline \multicolumn{4}{|l|}{ Specific anti-HDI IgG \% } \\
\hline HDI-ImmunoCAP & 5.0 & 11.2 & 10.5 \\
\hline $\mathrm{HDI}_{\mathrm{L}-\mathrm{HSA}}$ & 40.0 & 47.2 & 43.0 \\
\hline
\end{tabular}

Data are presented as arithmetic mean \pm SD and median (range), unless otherwise stated. HDI: hexamethylene di-isocyanate; COPD: chronic obstructive pulmonary disease; Ig: immunoglobulin; HDI: liquid HDI; HSA: human serum albumin; HDIV: HDI vapour. ${ }^{*}: \mathrm{n}=229 ;{ }^{*}: \mathrm{n=223}$; $^{+}$: chronic cough, chronic phlegm or shortness of

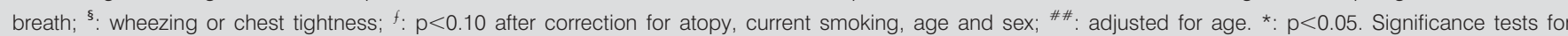
differences in the prevalence of symptoms and serology compared with office workers. Phadiatop and ImmunoCAP manufactured by Phadia (Uppsala, Sweden).

1.3 (0.9-1.7), $1.1(0.6-1.5)$ and $1.7(0.7-4.2)$, respectively). Specific IgE sensitisation was uncommon (below $\sim 4.4 \%$ ) while the prevalence of specific IgG sensitisation was higher (up to $47 \%$ among spray painters; table 1 ). Specific IgG sensitisation assessed by $\mathrm{HDI}_{\mathrm{L}}-\mathrm{HSA}, \mathrm{HDI}_{\mathrm{V}}$-HSA and N100-HSA was more common in highly exposed individuals (adjusted PRs IQR: 1.2, 1.7 and 1.9 , respectively; $p<0.1$ ). Fewer atopics were observed among individuals with high exposure (adjusted PR IQR 0.7, 95\% CI 0.6-0.9).

\section{BHR, spirometry and eNO}

BHR and baseline spirometry were not available for 14 workers because they could not produce an acceptable manoeuvre $(n=6)$ or were taking $\beta$-blockers $(n=3)$, or due to other medical reasons $(n=2)$ or refusal [2]. One person stopped during challenge because of health complaints. In 11 workers, eNO could not be determined because of problems with exhaling at a constant flow $(n=3)$, health complaints $(n=1)$, refusal $(n=3)$ and device errors $(n=4)$.
In table 2, BHR, baseline spirometry and eNO are presented for each job category. None of the office workers had BHR20 (BHR using a fall in FEV1 of $20 \%$ as a cut-off level (BHR20)), despite that, many reported asthma-like symptoms or were atopic. In contrast, $20 \%$ of spray painters were hyperresponsive. When using a fall in FEV1 of $15 \%$ as a cut-off level (BHR15), a prevalence of 15, 22 and $29 \%$ was found for office workers, other workers and spray painters, respectively. The FEV1/forced vital capacity (FVC) ratio and several flow parameters were significantly lower in spray painters compared with other workers. A total of 18 workers met the Global Initiative for Chronic Obstructive Lung Disease (GOLD) criteria for COPD (FEV1/FVC <70\%); 5, 4 and 15\% of office workers, other workers and spray painters, respectively. Of these, 12 fell into the GOLD I and six into the GOLD II category (four spray painters and two other workers). Geometric mean eNO levels ranged between 17.0 and $19.9 \mathrm{ppb}$ without significant differences between job title categories. 


\begin{tabular}{|c|c|c|c|c|}
\hline \multirow[t]{2}{*}{ TABLE 2} & \multicolumn{4}{|c|}{$\begin{array}{l}\mathrm{BHR}_{20}^{\#} \text {, baseline spirometry }{ }^{\top} \text { and exhaled nitric } \\
\text { oxide }(\mathrm{eNO})^{+}\end{array}$} \\
\hline & & $\begin{array}{c}\text { Office } \\
\text { workers }\end{array}$ & $\begin{array}{c}\text { Spray } \\
\text { painters }\end{array}$ & Others \\
\hline BHR20 \% & & 0 & 20.0 & 14.7 \\
\hline \multicolumn{5}{|c|}{ Lung function parameters } \\
\hline $\mathrm{FEV}_{1}$ & & $103.6 \pm 14.8$ & $101.6 \pm 14.1$ & $104.6 \pm 13.3$ \\
\hline FVC & & $103.6 \pm 16.5$ & $106.0 \pm 11.4^{\S}$ & $103.9 \pm 13.9$ \\
\hline $\mathrm{FEV}_{1} / \mathrm{FVC}$ & & $103.6 \pm 8.5$ & $98.7 \pm 11.3^{\S, f}$ & $103.6 \pm 10.0$ \\
\hline MMEF & & $92.9 \pm 22.7$ & $83.3 \pm 29.8^{f}$ & $94.8 \pm 28.7$ \\
\hline PEF & & $126.0 \pm 25.8$ & $114.9 \pm 20.2^{\S, f}$ & $121.8 \pm 21.7$ \\
\hline MEF75 & & $112.7 \pm 23.3$ & $100.5 \pm 26.7^{f}$ & $110.5 \pm 26.7$ \\
\hline MEF50 & & $98.4 \pm 26.0$ & $87.4 \pm 31.5^{f}$ & $96.5 \pm 29.2$ \\
\hline MEF25 & & $77.7 \pm 25.7$ & $72.6 \pm 31.5^{f}$ & $87.6 \pm 35.5$ \\
\hline eNO ppb & & $19.9 \pm 1.8$ & $17.0 \pm 1.9$ & $17.3 \pm 1.8$ \\
\hline $\begin{array}{l}\text { Data are pres } \\
\text { presented as } \\
\text { using a fall in } f \\
\text { level; FVC: fo } \\
\text { peak expirator } \\
\text { MEF50: maxin } \\
\text { expiratory flow } \\
\text { cantly differen } \\
(p<0.05) \text { after }\end{array}$ & $\begin{array}{l}\text { orced expire } \\
\text { rced vital } \\
\text { y flow; MEF } \\
\text { hum expirat } \\
\text { at } 25 \% \text { of v } \\
\text { from office } \\
\text { adjustment }\end{array}$ & $\begin{array}{l}\text { tic mean } \pm S D \text {, } \\
n \pm S D \text {. BHR20: } \\
\text { volume in one s } \\
\text { ity; MMEF: me } \\
\text { laximum expira } \\
\text { ow at } 50 \% \text { of } \\
\text { apacity. }{ }^{*}: n=2 \\
\text { kers; }{ }^{\circ} \text { : signific } \\
\text { current smokins }\end{array}$ & $\begin{array}{l}\text { unless otherwise } \\
\text { bronchial hyperr } \\
\text { econd (FEV } 1 \text { ) of } 2 \\
\text { ximal mid-expirat } \\
\text { ory flow at } 75 \% \text { o } \\
\text { ital capacity; ME } \\
4 ;{ }^{9}: \mathrm{n}=215 \text {; }^{+}: \mathrm{n}= \\
\text { ntly different from } \\
\text {, age, sex, height }\end{array}$ & $\begin{array}{l}\text { stated. eNO is } \\
\text { esponsiveness } \\
\text { ory as a cut-off } \\
\text { ory; PEF: } \\
\text { vital capacity; } \\
\text {-25: maximum } \\
=215 \text {; ' : signifi- } \\
\text { other workers } \\
\text { and atopy. }\end{array}$ \\
\hline
\end{tabular}

\section{Associations with exposure}

Hyperresponsiveness was clearly associated with exposure expressed as total NCO (table 3). Exposure-response relationships explored using smoothed spline plots confirmed this and showed similar log-linear associations for both BHR20 and BHR15. The occurrence of hyperresponsiveness increased gradually with increasing exposure without a clear indication for an exposure threshold (fig. 1a). The association between exposure and BHR remained, but became statistically borderline significant and slightly weaker, when COPD cases according to the GOLD criteria (FEV1/FVC $<70 \%$ ) were excluded from the analysis (adjusted PR IQR (CI): 1.8 (0.93.8 ) and 1.4 (0.9-2.4) for BHR20 and BHR15, respectively).

GOLD defined COPD (FEV1/FVC <70\%) was also strongly associated with exposure (table 3). Other determinants of FEV1/FVC $<70 \%$ were age and smoking, which were not associated with BHR.

No significant association between exposure and eNO was found for $\log$ eNO on a continuous scale or dichotomised with 75 th or 90th percentiles as cut-off points, with and without stratification for atopy and smoking.

To explore associations between exposure and potentially different asthma phenotypes, BHR20 was combined in different ways with $\mathrm{FEV} 1 / \mathrm{FVC}$, eNO or symptoms. BHR together with $\mathrm{FEV} 1 / \mathrm{FVC}<70 \%$ or eNO resulted in strong and (borderline) significant associations with exposure, respectively (table 3). Asthma-like symptoms with BHR20 were also strongly associated with exposure in a log-linear fashion (table 3; fig. 1b).

\begin{tabular}{|c|c|c|c|}
\hline \multirow[t]{2}{*}{ TABLE 3} & \multicolumn{3}{|c|}{$\begin{array}{l}\text { Association between (combined) health end- } \\
\text { points and isocyanate (NCO) exposure for an } \\
\text { interquartile range increase (NCO exposure } 0.3- \\
2799 \mu \mathrm{g} \cdot \mathrm{m}^{-3} \cdot \mathrm{h} \cdot \mathrm{month}^{-1} \text { ) in exposure adjusted for } \\
\mathrm{smoking} \text {, age, sex and atopy }\end{array}$} \\
\hline & & Subjects $n$ & PR $(95 \% \mathrm{Cl})$ \\
\hline \multicolumn{2}{|c|}{ BHR20 } & 33 & $2.0(1.1-3.8)$ \\
\hline \multicolumn{2}{|c|}{$\mathrm{FEV}_{1} / \mathrm{FVC}<\mathbf{7 0} \%$} & 18 & $2.7(1.1-6.8)$ \\
\hline \multicolumn{2}{|c|}{ eNO ppb $\geqslant 90$ th percentile } & 22 & $0.8(0.4-1.6)^{\#}$ \\
\hline \multicolumn{4}{|c|}{ Combined parameters } \\
\hline \multicolumn{2}{|c|}{$\mathrm{BHR}_{20}+\mathrm{FEV}_{1} / \mathrm{FVC}<70 \%$} & 10 & $6.1(1.2-31.7)^{\#}$ \\
\hline \multicolumn{2}{|c|}{$\mathrm{BHR} 20+\mathrm{eNO} \mathrm{ppb} \geqslant 90$ th percentile } & 6 & $7.0(0.7-72.1)^{\bullet}$ \\
\hline \multicolumn{2}{|c|}{ BHR20 + asthma-like symptoms } & 19 & $2.7(1.0-6.8)$ \\
\hline \multicolumn{2}{|c|}{ BHR20 + COPD-like symptoms } & 15 & $1.5(0.6-3.9)$ \\
\hline \multicolumn{2}{|c|}{ BHR20 + work-related chest tightness } & 3 & $0.9(0.1-8.3)^{+}$ \\
\hline \multicolumn{2}{|c|}{ BHR20 + work-related rhinitis } & 10 & $2.2(0.6-8.0)^{\S}$ \\
\hline \multicolumn{2}{|c|}{ BHR20 + work-related conjunctivitis } & 7 & $4.3(0.7-28.0)^{\S}$ \\
\hline
\end{tabular}

PR: prevalence ratio; Cl: confidence interval; BHR20: bronchial hyperresponsiveness using a fall in forced expiratory volume in one second (FEV 1 ) of $20 \%$ as a cut-off level; FVC: forced vital capacity; eNO: exhaled nitric oxide; COPD: chronic obstructive pulmonary disease. ${ }^{\#}$ : adjusted for smoking and atopy

$\because$ : adjusted for smoking and age; adjustment for atopy resulted in similar PR

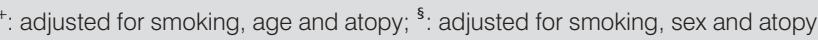

Highly exposed individuals had lower FEV1, FEV1/FVC and flow-volume parameters (table 4). For all parameters except maximum expiratory flow at $25 \%$ of vital capacity, associations differed between atopic and nonatopic individuals $(\mathrm{p}<0.05)$. Surprisingly, after stratification these associations between lung function and exposure were especially found in nonatopic workers. Smoothed spline plots showed that at medium-tohigh exposure levels exposure-response relationships in atopic individuals run parallel to those observed in nonatopic individuals. However, low exposed-atopic individuals showed a systematically lower lung function. Consequently, associations with exposure within atopic individuals were not statistically significant (data not shown). When hyperresponsive individuals were excluded from the analyses, similar associations between exposure and lung function were found. Excluding the workers with only one technically acceptable baseline manoeuvre also did not affect the association between lung function parameters or BHR and exposure.

\section{Associations with serology and symptoms}

Overall, sensitised (specific $\operatorname{IgE}$ and $\operatorname{IgG}$ ) workers were more often hyperresponsive (table 5). This was statistically significant for IgG measured only with the ImmunoCAP assay. eNO was not associated with a specific IgE antibody response to isocyanates, but was increased in workers with specific IgG against N3300-HSA or N100-HSA (table 5). When restricting this analysis to nonsmoking subjects without atopy these associations were much stronger ( $\beta$ log exposures 0.303 $(p=0.02)$ and $0.357(p=0.001)$ for IgG against N3300-HSA and N100-HSA, respectively) and was also statistically significant for $\mathrm{IgG}$ against $\mathrm{HDI}_{\mathrm{V}}$-HSA ( $\beta \log$ exposure 0.329; $\mathrm{p}=0.02)$. 

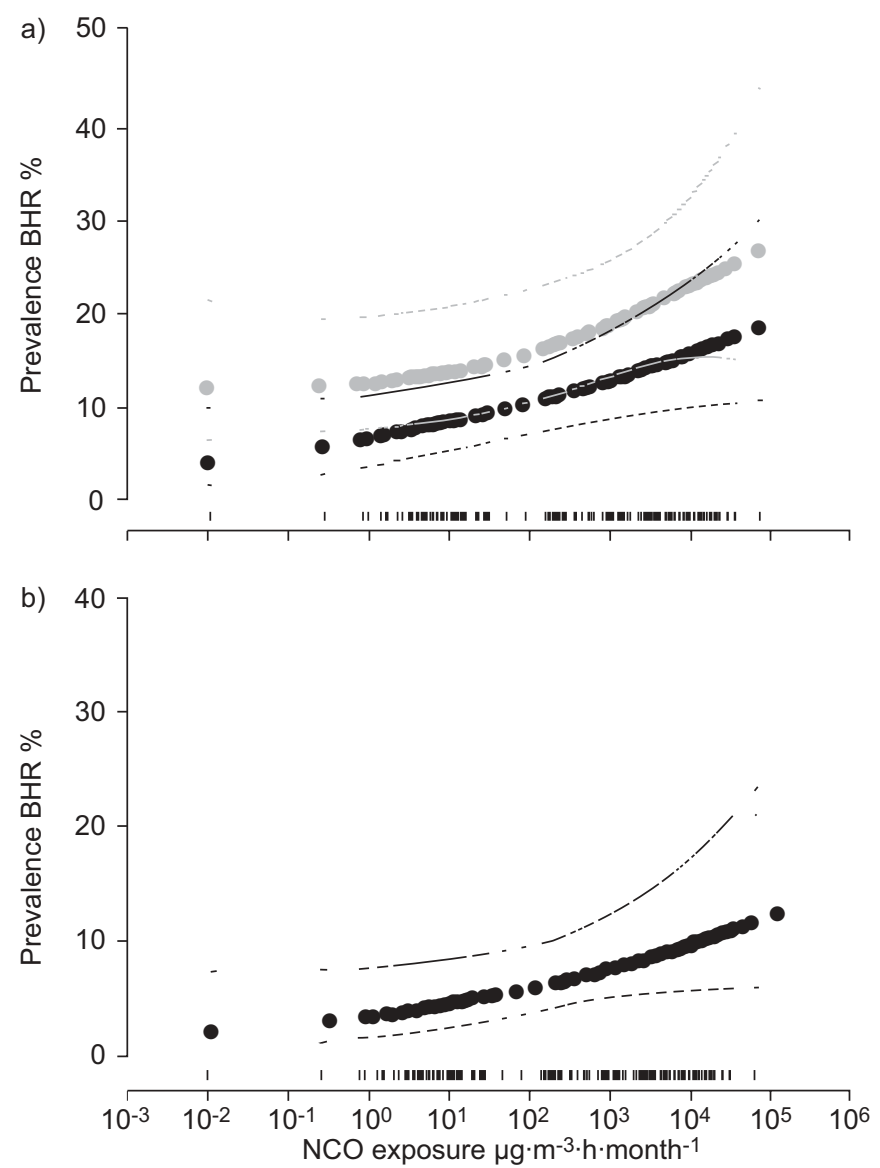

FIGURE 1. Association between log-linear exposure to isocyanates (NCO) and health end-points. Penalised smoothed spline plots with smoothed $95 \%$ confidence interval. a) Bronchial hyperresponsiveness (BHR20; - ) and BHR15 ( $\bullet$ and b) BHR20 and asthma-like symptoms. a and b) Splines are nonsignificant. BHR20: bronchial hyperresponsiveness using a fall in forced expiratory volume in one second (FEV 1 ) of $20 \%$ as a cut-off level; BHR15: bronchial hyperresponsiveness using a fall in FEV1 of $15 \%$ as a cut-off level.

Workers with asthma-like symptoms had significantly more BHR and significantly lower baseline FEV1, FEV1/FVC ratio and maximal mid-expiratory flow. COPD-like symptoms and work-related rhinitis were (borderline) significantly associated with BHR as reported previously [7]. Statistically significant increased eNO levels were found in workers with reported asthma-like symptoms and work-related rhinitis and conjunctivitis (adjusted PR (95\% CI): 1.7 (1.1-2.5), $1.6(1.1-2.4)$ and 1.9 (1.1-3.6), respectively).

\section{DISCUSSION}

In the present study, a clear and positive association was found between exposure to isocyanate oligomers and BHR. Exposure-related obstructive lung function changes (FEV1, FEV1/FVC ratio and flow parameters) independent of BHR were also found. These results point towards different exposure-related respiratory phenotypes related to occupational isocyanate exposure. The findings also support previous observations [7] that asthma-like and COPD-like symptoms are associated with isocyanate exposure level in workers exposed to mainly HDI oligomers in the spray painting industry.

\begin{tabular}{lcccccc}
\hline TABLE 4 & $\begin{array}{l}\text { Association between lung function parameters } \\
\text { and exposure adjusted for current smoking, age, } \\
\text { sex, height and atopy }\end{array}$ \\
& All & p-value & Nonatopics & p-value & Atopics & p-value \\
\hline FEV 1 & -0.004 & 0.60 & -0.017 & 0.08 & $0.012^{*}$ & 0.27 \\
FVC & 0.015 & 0.08 & 0.010 & 0.37 & 0.020 & 0.10 \\
FEV 1 /FVC & -0.321 & 0.004 & -0.543 & 0.0002 & $-0.088^{*}$ & 0.61 \\
PEF & -0.026 & 0.31 & -0.088 & 0.01 & $0.045^{*}$ & 0.22 \\
MMEF & -0.037 & 0.03 & -0.071 & 0.003 & $0.0014^{\star}$ & 0.95 \\
MEF75 & -0.043 & 0.13 & -0.109 & 0.01 & $0.032^{*}$ & 0.42 \\
MEF50 & -0.037 & 0.07 & -0.076 & 0.01 & $0.010^{*}$ & 0.72 \\
MEF25 & -0.024 & 0.02 & -0.038 & 0.002 & -0.010 & 0.51 \\
\hline
\end{tabular}

Data are expressed as $\beta$ log exposures, unless otherwise stated. FEV1: forced expiratory volume in one second; FVC: forced vital capacity; PEF: peak expiratory flow; MMEF: maximal mid-expiratory flow; MEF75: maximal expiratory flow at $75 \%$ of vital capacity; MEF50: maximal expiratory flow at $50 \%$ of vital capacity; MEF25: maximal expiratory flow at $25 \%$ of vital capacity. *: significantly different, $p<0.05$

\begin{tabular}{cccc} 
TABLE 5 & $\begin{array}{l}\text { Associations between bronchial } \\
\text { hyperresponsiveness and specific sensitisation, } \\
\text { and between exhaled nitric oxide (eNO) and } \\
\text { specific sensitisation adjusted for current } \\
\text { smoking, age, sex and atopy }\end{array}$ \\
\multicolumn{4}{c}{ BHR20 } \\
Log eNO ppb & p-value \\
\hline Specific IgE & $1.62(0.30-8.85)^{\#}$ & 0.312 & \\
HDI-ImmunoCAP & $1.69(0.53-5.45)^{\#}$ & 0.182 & 0.24 \\
HDIL-HSA & $2.32(0.52-10.31)^{\#}$ & -0.043 & 0.37 \\
HDIV-HSA & $1.96(0.39-9.93)^{\#}$ & 0.320 & 0.30 \\
N3300-HSA & $2.38(0.75-7.57)^{\#}$ & 0.190 & 0.35 \\
N100-HSA & & & \\
Specific IgG & $3.07(1.14-8.22)$ & 0.153 & 0.20 \\
HDI-ImmunoCAP & $0.76(0.40-1.45)$ & 0.040 & 0.58 \\
HDIL-HSA & $1.06(0.45-2.49)$ & 0.064 & 0.52 \\
HDIV-HSA & $1.28(0.61-2.69)$ & 0.169 & 0.07 \\
N3300-HSA & $1.03(0.52-2.05)$ & 0.156 & 0.05 \\
N100-HSA & & \\
\hline
\end{tabular}

Data are presented as prevalence ratio (95\% confidence interval), unless otherwise stated. BHR20: bronchial hyperresponsiveness using a fall in forced expiratory volume in one second of $20 \%$ as a cut-off level; Ig: immunoglobulin; HDI: hexamethylene di-isocyanate; HDIL: liquid HDI; HSA: human serum albumin; HDIv: HDI vapour. ${ }^{\#}$ : adjusted for current smoking, sex and atopy. ImmunoCAP manufactured by Phadia (Uppsala, Sweden).

BHR is closely related to variable airway obstruction and is usually considered a hallmark of asthma in epidemiological studies [15]. The direct associations between BHR and exposure, which were independent from chronic obstruction, as well as the association with asthma-like symptoms are suggestive of isocyanate-induced asthma-like respiratory effects. BHR and asthma-like symptoms (wheezing or chest tightness) taken together appeared even more strongly related 
to exposure. Two previous studies have assessed BHR on the population level in isocyanate exposed workers, which both did not incorporate exposure measurements. A study by REDLICH et al. [16] showed a similar pattern of BHR across job title categories in car body repair shop workers, exposed to HDI-based paint, which did not reach statistical significance, likely due to the small sample size. In a case-control study among furniture workers, exposed to toluene di-isocyanate based paint, BHR was not more prevalent among painters than among assembly and wood workers [17].

Isocyanate exposure was also associated with obstructive respiratory changes. Accelerated lung function decline has been demonstrated in adults with self-reported asthma [18] and a recent study suggests that occupational asthma results in faster rates of decline than nonoccupational asthma [19]. Although these changes may be observed in specific subgroups of asthmatics [20], effects on lung function are usually not observed in the population at large in healthy working populations exposed to occupational allergens. BHR in the presence of airway obstruction (FEV1/FVC $<70 \%$ ) was strongly associated with exposure to isocyanates in the current study. This may reflect asthma-related chronic effects. Yet, the association between lung function parameters and exposure was also found in nonatopic workers without BHR. Since asthma was probably not manifest in these workers, other mechanisms are likely involved. Lung function decline caused by toluene di-isocyanate has been previously described, but could not be reproduced in later studies [21]. Isocyanaterelated effects on lung function have also previously been reported for spray painters exposed to HDI. A similarly sized cross-sectional study reported an association between estimated exposure levels and expiratory flow rates in aircraft painters [22]. A smaller longitudinal study that included exposure measurements found an association in smokers between FEV1, FVC and vital capacity and the frequency of peak exposures but not with mean levels [23]. Interestingly, the present authors only found significant associations with lung function in nonatopic workers. Since smoking was not associated with atopic status, it seems unlikely that smoking is responsible for the observed differences between atopic and nonatopic subjects in the current study.

Specific IgE was found in only one of the 19 workers with both $\mathrm{BHR}$ and asthma-like symptoms and in none of the nine workers with both BHR and an FEV1/FVC ratio of $<70 \%$. These results indicate that asthma-like respiratory effects including lower respiratory symptoms and BHR can not be attributed to specific IgE antibodies using the isocyanate antigen preparations available in the present population. Although a range of conjugates were used, the conjugation reactions in the human airways are unknown and it is possible that an IgE mediated response could be demonstrated using a different conjugate. However, alternative explanations also exist. First, cell-mediated allergy or irritant mechanisms may be involved [4, 24]. Secondly, exacerbations of pre-existing asthma due to isocyanate exposure may explain the findings to some extent and cannot be excluded. Yet, the clear exposurerelated difference in the prevalence of BHR seems more suggestive of isocyanate-associated asthma than for exacerbations of pre-existing asthma.
The association between IgG to HDI-ImmunoCAP and BHR in the absence of an association between HDI-ImmunoCAP and exposure is remarkable and needs further exploration. The presence of specific IgG antibodies also seemed associated with elevated eNO levels.

eNO is thought to be a direct marker of eosinophilic inflammation immediately after exposure $[25,26]$, while BHR probably reflects the continuous process of airway wall remodelling [27]. A specific inhalation study has reported a significant increase in eNO in asthmatics who were isocyanateresponders and of whom $25 \%$ showed di-isocyanate specific IgE antibodies [28]. The current authors showed that eNO is associated with symptoms and BHR, but found no clear association with isocyanate exposure. Interestingly, BHR in the presence of high eNO levels was strongly associated with exposure. Combining BHR and eNO may have resulted in a distinct subgroup of allergic asthmatics [27]. Although specific $\mathrm{IgE}$ to any of the isocyanate conjugates was not found in any of the six workers with BHR and high eNO levels, all of these individuals were atopic.

The main strength of the present study is the quantitative inhalation exposure assessment component, which contributes considerably to the discriminative power of the study. Some misclassification of exposure may have occurred since the use of personal protective equipment, previous exposures and dermal exposure were not taken into account. Yet, the incorporation of quantitative exposure estimates based on over 500 inhalation exposure measurements and detailed task activity information is an improvement over most previous epidemiological studies on isocyanates, which generally relied on qualitative exposure assessment. Only one previous epidemiological study included exposure measurements of isocyanate oligomers [23], but that study was of limited size. Another strength is the inclusion of several objective respiratory effect measures, which have not been investigated together in one population before.

A limitation of the present study is that it was performed in a complex exposure environment, complicating the establishment of causal relationships. It should be considered that isocyanates have strong irritating properties and are therefore very likely the most relevant irritant in the spray painting environment. However, exposure to other irritants may occur. Solvents, which may be associated with respiratory effects [29], are another major component of paint. Some exposure measurements focused on solvents were performed in the current study (data not shown). Exposure levels were all well below existing occupational exposure limits. Highest exposure levels were found for nonspray-painting tasks, such as tasks involving solvent based fillers and degreasers, and solvent exposure did not correlate with isocyanate exposure. Therefore, it seems unlikely that solvents are responsible for the associations found in the current study. Other exposures with possibly irritating properties include welding fumes and sanding dust. These exposures are experienced mainly by auto body workers, which are included in the other workers category, and cannot explain the higher risks found for spray painters.

A limitation of the categorisation of the self-reported symptoms into asthma-like and COPD-like symptoms is that chronic 
cough and shortness of breath can be present in both asthma and COPD resulting in misclassification. The distinction between asthma and COPD, which are both phenotypic heterogeneous diseases characterised by obstructive airflow limitation and inflammatory changes in the respiratory tract is difficult and the present study was not directed to establish or confirm a diagnosis of respiratory disease.

Another limitation is that because this is a healthy population, bronchodilators were not administered before baseline spirometry. This may have resulted in overestimation of chronic airflow limitation in the present study [30], while variable airflow limitation may have been underestimated.

The participation rate of the current study was acceptable. However, the time consuming and more invasive tests in the present study compared with the baseline study may have led to a participation bias. Although overall the prevalence of symptoms and serology was similar to the baseline study, office workers showed a higher prevalence of symptoms and atopy. As a result associations with exposure were less strong than in the baseline study [7]. In both the current and the baseline study, atopy was less common among workers with high exposure, which the present authors interpreted as indicative of a healthy worker effect.

Despite these limitations and potential biases, clear associations were found between respiratory effects and isocyanate exposure.

In conclusion, the current study provides evidence of the existence of independent exposure-related respiratory phenotypes associated with occupational isocyanate exposure. Besides asthma, with bronchial hyperresponsiveness as a hallmark, chronic obstructive effects were found. The different phenotypical subgroups with respect to bronchial hyperresponsiveness, airway obstruction, antibodies, and increased exhaled nitric oxide may point towards heterogeneity in underlying mechanisms. The results indicate that at exposure levels commonly found in this industry [8] isocyanate oligomers can induce respiratory health effects, stressing the importance of regulation and control of isocyanate oligomer exposure.

\section{ACKNOWLEDGEMENTS}

The present authors would like to acknowledge the following individuals for their contribution the current study. All company owners and workers who cooperated and made this study possible. M. Zengeni, R. Senf, S. de Wind, W. Munneke, E. Meijer and M. Oldewening (all Environmental Epidemiology, Institute for Risk Assessment Sciences, Utrecht University, Utrecht, the Netherlands) for their contribution to the field work. A. Wisnewski (Dept of Internal Medicine, Yale School of Medicine, New Haven, CT, USA), M. RaulfHeimsoth (Research Institute for Occupational Medicine of the Berufsgenossenschaften, Ruhr University, Bochum, Germany) and M. Boeve (Environmental Epidemiology, Institute for Risk Assessment Sciences) for their contribution to the serological analyses. In addition, the current authors would like to thank the Dutch Branch Organisation for Car Body Repair Shops (FOCWA; Sassenheim, the Netherlands) for their contribution to the enrolment of companies.

\section{REFERENCES}

1 Bernstein JA. Overview of diisocyanate occupational asthma. Toxicology 1996; 111: 181-189.

2 Vandenplas O, Malo JL, Saetta M, Mapp CE, Fabbri LM. Occupational asthma and extrinsic alveolitis due to isocyanates: current status and perspectives. $\mathrm{Br} J$ Ind Med 1993; 50: 213-228.

3 Wisnewski AV, Redlich CA. Recent developments in diisocyanate asthma. Curr Opin Allergy Clin Immunol. 2001; 1: 169-175.

4 Wisnewski AV, Redlich C, Mapp C, Bernstein DI. Polyisocyanates and their prepolymers. In: Bernstein IL, Chan-Yeung M, Malo JL, Bernstein DI, eds. Asthma in the workplace. 3rd Edn. New York, Taylor and Francis Group, 2006; pp. 481-504.

5 Lesage J, Goyer N, Desjardins F, Vincent JY, Perrault G. Workers' exposure to isocyanates. Am Ind Hyg Assoc J 1992; 53: 146-153.

6 Streicher RP, Reh CM, Key-Schwartz RJ, Schlecht PC, Cassinelli ME, O'Connor PF. Determination of airborne isocyanate exposure: considerations in method selection. Am Ind Hyg Assoc J 2000; 61: 544-556.

7 Pronk A, Preller L, Raulf-Heimsoth M, et al. Respiratory symptoms, sensitization, and exposure response relationships in spray painters exposed to isocyanates. Am J Respir Crit Care Med 2007; 176: 1090-1097.

8 Pronk A, Tielemans E, Skarping G, et al. Inhalation exposure to isocyanates of car body repair shop workers and industrial spray painters. Ann Occup Hyg 2006; 50: 1-14.

9 American Thoracic Society/European Respiratory Society. ATS/ERS recommendations for standardized procedures for the online and offline measurement of exhaled lower respiratory nitric oxide and nasal nitric oxide, 2005. Am J Respir Crit Care Med 2005; 171: 912-930.

10 Alving K, Janson C, Nordvall L. Performance of a new hand-held device for exhaled nitric oxide measurement in adults and children. Respir Res 2006; 7: 67.

11 Khalili B, Boggs PB, Bahna SL. Reliability of a new handheld device for the measurement of exhaled nitric oxide. Allergy 2007; 62: 1171-1174.

12 Menzies D, Nair A, Lipworth BJ. Portable exhaled nitric oxide measurement: comparison with the "gold standard" technique. Chest 2007; 131: 410-414.

13 Skov T, Deddens J, Petersen MR, Endahl L. Prevalence proportion ratios: estimation and hypothesis testing. Int $J$ Epidemiol 1998; 27: 91-95.

14 Hastie T, Tibshirani RJ, eds. Generalized Additive Models (Monographs on Statistics and Applied Probability). New York, Chapman and Hall, 1990.

15 Becklake MR, Malo JL, Chan-Yeung M. Epidemiological approaches in occupational asthma. In: Bernstein IL, ChanYeung M, Malo JL, Bernstein DI, eds. Asthma in the workplace. 3rd Edn. New York, Taylor and Francis Group, 2006; pp. 37-86.

16 Redlich CA, Stowe MH, Wisnewski AV, et al. Subclinical immunologic and physiologic responses in hexamethylene diisocyanate-exposed auto body shop workers. Am J Ind Med 2001; 39: 587-597.

17 Talini D, Monteverdi A, Benvenuti A, et al. Asthma-like symptoms, atopy, and bronchial responsiveness in furniture workers. Occup Environ Med 1998; 55: 786-791. 
18 Lange P, Parner J, Vestbo J, Schnohr P, Jensen G. A 15-year follow-up study of ventilatory function in adults with asthma. N Engl J Med 1998; 339: 1194-1200.

19 Anees W, Moore VC, Burge PS. FEV1 decline in occupational asthma. Thorax 2006; 61: 751-755.

20 Portengen L, Hollander A, Doekes G, de Meer G, Heederik D. Lung function decline in laboratory animal workers: the role of sensitisation and exposure. Occup Environ Med 2003; 60: 870-875.

21 Ott MG. Occupational asthma, lung function decrement, and toluene diisocyanate (TDI) exposure: a critical review of exposure-response relationships. Appl Occup Environ Hyg 2002; 17: 891-901.

22 Glindmeyer HW, Lefante JJ Jr, Rando RJ, Freyder L, Hnizdo E, Jones RN. Spray-painting and chronic airways obstruction. Am J Ind Med 2004; 46: 104-111.

23 Tornling G, Alexandersson R, Hedenstierna G, Plato N. Decreased lung function and exposure to diisocyanates (HDI and HDI-BT) in car repair painters: observations on re-examination 6 years after initial study. Am J Ind Med 1990; 17: 299-310.
24 Raulf-Heimsoth M, Baur X. Pathomechanisms and pathophysiology of isocyanate-induced diseases-summary of present knowledge. Am J Ind Med 1998; 34: 137-143.

25 Olin AC, Alving K, Toren K. Exhaled nitric oxide: relation to sensitization and respiratory symptoms. Clin Exp Allergy 2004; 34: 221-226.

26 Simpson A, Custovic A, Pipis S, Adisesh A, Faragher B, Woodcock A. Exhaled nitric oxide, sensitization, and exposure to allergens in patients with asthma who are not taking inhaled steroids. Am J Respir Crit Care Med 1999; 160: 45-49.

27 Henriksen AH, Lingaas-Holmen T, Sue-Chu M, Bjermer L. Combined use of exhaled nitric oxide and airway hyperresponsiveness in characterizing asthma in a large population survey. Eur Respir J 2000; 15: 849-855.

28 Barbinova L, Baur X. Increase in exhaled nitric oxide (eNO) after work-related isocyanate exposure. Int Arch Occup Environ Health 2006; 79: 387-395.

29 Schenker MB, Jacobs JA. Respiratory effects of organic solvent exposure. Tuber Lung Dis 1996; 77: 4-18.

30 Sterk PJ. Let's not forget: the GOLD criteria for COPD are based on post-bronchodilator FEV1. Eur Respir J 2004; 23: 497-498. 